\title{
What a general paediatrician needs to know about early life programming
}

\author{
Thomas C Williams, ${ }^{1}$ Amanda J Drake ${ }^{2}$
}

${ }^{1}$ Neonatal Unit, Simpson Centre for Reproductive Health, Royal Infirmary of Edinburgh, Edinburgh, UK ${ }^{2}$ University/British Heart Foundation Centre for Cardiovascular Science, University of Edinburgh, The Queen's Medical Research Institute, Edinburgh, UK

\section{Correspondence to} Dr Amanda J Drake, University/BHF Centre for Cardiovascular Science, University of Edinburgh, The Queen's Medical Research Institute, Edinburgh, EH16 4TJ, UK; mandy.drake@ed.ac.uk

Received 5 March 2015 Revised 20 April 2015 Accepted 28 April 2015 Published Online First 19 May 2015

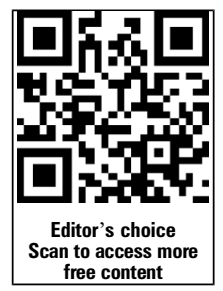

\section{ABSTRACT}

The process whereby early exposure to an adverse environment has an influence on later life outcomes has been called 'early life programming'. While epidemiological evidence for this has been available for decades, only in recent years have the mechanisms, in particular epigenetic modifications, for this process begun to be elucidated. We discuss the evidence for early life programming, the possible mechanisms, how effects may be transmitted across generations, and conclude by looking at some examples relevant to general paediatrics.

\section{CHILDHOOD AND LATER DISEASE RISK}

The fact that early exposures might have an influence on health outcomes later in life has been recognised since the first half of the 20th century. In 1933 Kermack et $a l^{1}$ analysed historic death rates data for England, Scotland and Sweden and noted that "the figures behave as if the expectation of life was determined by the conditions which existed during the child's earlier years". They further speculated that "improvement in infantile mortality is dependent in large measure on improvement in maternal health". In 1977 Forsdahl $^{2}$ correlated higher infant mortality in Norway with a later increased risk of death from cardiovascular causes. He proposed poverty in childhood and adolescence followed by prosperity as a risk factor for cardiovascular disease (CVD), and hypothesised that "some form of permanent damage caused by a nutritional deficit" might be involved.

\section{THE BARKER HYPOTHESIS}

Ongoing epidemiological work continued to show an association between low birth weight and a higher risk of CVD, stroke, the metabolic syndrome and osteoporosis in later life. Barker and colleagues, ${ }^{3}$ in a series of papers argued that a fetus faced with undernutrition slows its growth rate to reduce its nutritional requirements, but this period of undernutrition might also lead to reduced function in key organs, altered metabolic and endocrine feedback loops, and an increased vulnerability to adverse environmental stressors. Over time these ideas have developed into the Developmental Origins of Health and Disease concept, whereby early life exposures are thought to lead to 'programming' of cardiovascular, neuroendocrine and metabolic systems, predisposing the individual to later life non-communicable diseases (NCDs).

Some authors have put this concept of programming within an evolutionary paradigm with the idea of the 'predictive adaptive response'. ${ }^{4}$ They argue that these stereotyped responses to an adverse early life environment are adaptive in the short term, and particularly when individuals continue to live in a resource-poor environment, represent the best way to guarantee they reach reproductive age themselves. However, in a resource-rich postnatal environment such as that of the developed world, these programmed changes might have the (unanticipated) effect of predisposing affected individuals to an increased risk of NCDs in adulthood (figure 1). Regardless of the validity of the idea of a 'predictive adaptive response', in recent years focus has shifted from extremes of birth weight to how programming might occur across all pregnancies and in individuals with birth weights within the normal range.

\section{ADVERSE ENVIRONMENTS IN UTERO}

A large number of human cohort studies have demonstrated a link between lower birth weight (suggesting in utero exposure to an adverse environment) and a higher risk of CVD, stroke, insulin resistance and type 2 diabetes in adulthood, in a variety of settings in the developed and developing world, ${ }^{4}$ and these findings have been replicated extensively in animal studies. ${ }^{5}$ In addition to cardiometabolic sequelae, low birth weight has also been related to increased risk of death from infectious causes, ${ }^{6}$ altered immune function, an increased risk of asthma and atopic dermatitis, ${ }^{7}$ and neurodevelopmental disorders such as attention deficit hyperactivity disorder ${ }^{8}$ and schizophrenia. ${ }^{9}$ The importance of the early life environment in influencing later disease risk has been highlighted by a recent analysis showing that the greater the number of adverse early life risk factors an individual is exposed to, the greater the risk of overweight and obesity in childhood. ${ }^{10}$

Although many of the original studies focused on poor maternal nutrition as a major contributor to low birth weight, a wide variety of endogenous and exogenous factors are now recognised to influence cardiovascular, respiratory, metabolic and neurodevelopmental outcomes in offspring. Animal models using uterine artery ligation to create in utero hypoxia have shown that offspring are at risk of cardiovascular and metabolic complications. ${ }^{5}$ Similarly, human studies suggest that maternal hypertension ${ }^{11}$ and cigarette smoking, ${ }^{12}$ which lead to in utero hypoxia, also increase the risk of CVD. Although the original epidemiological studies did not distinguish between intrauterine growth restriction (IUGR) and prematurity as a cause of low birth weight, it is increasingly realised that prematurity itself is a major risk factor for the development of NCDs (reviewed in refs. 13 and 14). 
Figure 1 Early life programming and later disease risk. Exposure to an adverse early life environment results in changes which may maximise short-term and long-term survival but which can result in an increased risk of disease in later life. Such programmed effects may also include strategies to maximise reproductive success and population/species survival.

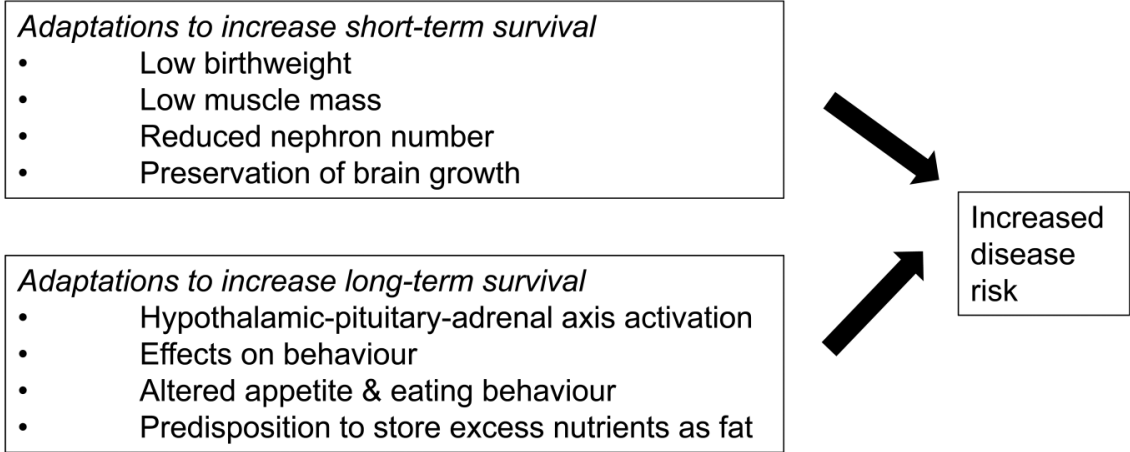

\begin{tabular}{|l|}
\hline $\begin{array}{l}\text { Adaptations to maximise reproductive success } \\
\text { - Early puberty and early reproduction }\end{array}$ \\
\hline
\end{tabular}

Adaptations to ensure family/population/species survival

- Intergenerational effects
Interestingly, maternal obesity/overnutrition during pregnancy, which commonly leads to increased birth weight, also associates with adverse offspring health outcomes which, perhaps surprisingly, are similar to those seen with undernutrition. In animal and human studies maternal overnutrition is linked with an increased predisposition to obesity, hypertension, hyperinsulinaemia, hyperglycaemia, and increased plasma triglycerides, cholesterol and leptin in offspring. ${ }^{15}$ In humans, maternal obesity has also been linked to an increased risk of attention deficit hyperactivity disorder and problems with emotional regulation ${ }^{16}$ and with premature mortality from cardiovascular events. ${ }^{17}$

Prenatal glucocorticoid overexposure is also associated with programmed effects. Epidemiological studies show that pregnant mothers exposed to a significant life event (death of a loved one, exposure to terrorism or a natural disaster) give birth to infants with a lower birth weight, ${ }^{18}$ who have an increased risk of impaired cognition. ${ }^{19}$ Maternal stress is also associated with effects on neurodevelopment in neonates, manifesting as lower scores on neonatal assessment, ${ }^{20}$ behavioural and emotional problems at the age of 4 years, ${ }^{21}$ decreased grey matter density, ${ }^{22}$ and lower cognitive and language abilities in childhood. ${ }^{19}$ The children of mothers treated with glucocorticoids because of a risk that the unborn child has congenital adrenal hyperplasia appear to be at risk of worse cognitive function than controls. $^{23}$ Studies in rodent, sheep and non-human primate models show an association between antenatal glucocorticoid exposure (exogenous and endogenous), raised blood pressure (BP) and altered glucose-insulin homoeostasis, neuroendocrine function and behaviour. ${ }^{24}$ Finally, a variety of other adverse environmental factors have been shown to impact on neurodevelopmental outcomes: maternal infection, alcohol consumption, recreational drug use, treatment with certain medications (eg, sodium valproate) and prenatal exposure to toxins such as arsenic and lead have all been associated with an increased risk of adverse neurodevelopmental outcomes including schizophrenia and autism (reviewed in ref. 25).

\section{POSTNATAL FACTORS WHICH INFLUENCE THE RISK OF DEVELOPING NCD}

The long-term consequences of early exposures are modulated by the postnatal environment. Early postnatal growth patterns influence disease risk, for example, in a trial involving a cohor of small for gestational age (SGA) infants, those randomised to a high protein formula who had greater weight gain had significantly higher BP at 6-8 years, ${ }^{26}$ and conditional gains in abdominal circumference also associate with higher childhood $\mathrm{BP}^{27}$ Three large cohort studies have shown that excessive weight gain in infancy is associated with an increased risk of greater total fat mass and percentage body fat, lower insulin sensitivity and higher systolic BP in childhood. ${ }^{28}$ These relationships are complex, however; extensive data from the Helsinki birth cohort study and the Hertfordshire cohort show that low weight at 1 year of age but an early 'adiposity rebound' associates with a higher risk of CVD and type 2 diabetes and that boys who were born small but were tall at school entry had a 6 -year reduction in life span. ${ }^{29} 30$ These data are supported by animal studies, for example, in mice, poor fetal growth resulting from maternal protein restriction, followed by rapid postnatal growth results in reduced life span. ${ }^{31}$

Because of phenotypical similarities between adults born SGA and prematurely, some researchers have postulated that while in low birthweight infants the adverse environment is experienced in utero, in preterm infants these environmental challenges occur postnatally. ${ }^{32}$ Preterm birth, regardless of birth weight relative to gestation (ie, without evidence of in utero growth restriction), has in itself has been associated with a reduction in insulin sensitivity, ${ }^{32} 33$ changes in the endocrine regulation of childhood growth ${ }^{34}$ and increased adiposity. ${ }^{35}$ Similar to SGA infants, rapid early weight gain may also be detrimental for preterm babies: in a randomised controlled trial which allocated preterm infants to high or lower nutrient diets, those with the most rapid weight gain in the first 2 weeks of life showed evidence of insulin resistance in adolescence ${ }^{36}$ and other studies report that upward centile crossing for weight in infancy ${ }^{37}$ and childhood $^{38}$ are associated with insulin resistance and higher BP.

However, low birth weight and preterm infants are susceptible to the influences of postnatal diet, and maternal obesity and overnutrition are risk factors for childhood obesity, and this is exacerbated by a high energy diet in infancy. ${ }^{39}$ In rodent models of maternal overfeeding, offspring are predisposed to obesity and metabolic abnormalities, and this effect is amplified when the offspring are exposed to high-fat diets following 
weaning. ${ }^{40}$ Finally, there may be an important influence of childhood exposure to stressful experiences; severe stress during childhood is a well known risk factor for mental health disorders and CVD. ${ }^{41}$

\section{MECHANISMS}

A consistent criticism of the Developmental Origins of Health and Disease concept has been the difficulty in disentangling the putative effects of programming from the shared genetic and environmental influences affecting offspring. Nevertheless, studies in humans and in animal models have attempted to address a number of potential mechanisms.

Programming may exercise its long-term effects via structural changes in organs. Human infants born after IUGR have reduced numbers of nephrons, ${ }^{42}$ increasing the risk of hypertension in adulthood. Prematurity has also been associated with a reduction in capillary density, thought to be related to an increased risk of hypertension. ${ }^{43}$ In animal models, antenatal glucocorticoid exposure leads to reduced nephron number and changes in cardiac noradrenergic innervation ${ }^{24}$ together with a reduction in pancreatic $\beta$-cell growth, a risk factor for type 2 diabetes. ${ }^{44}$ Maternal obesity impacts on offspring body fat and muscle composition, which may contribute towards the development of insulin resistance. ${ }^{15}$ Antenatal glucocorticoids affect hippocampal growth, and associate with delayed maturation of neurons, myelination, glia and vasculature. ${ }^{24}$

Programming may also lead to longer-term hormonal changes. In rodents, prenatal glucocorticoid excess affects the renin-angiotensin-aldosterone system and undernutrition and glucocorticoid overexposure affect glucose-insulin homoeostasis in a variety of animal models. ${ }^{24}$ Maternal obesity/overnutrition during pregnancy leads to programmed alterations in the brain, in particular the hypothalamus, which may impact on appetite control. ${ }^{15}$ Importantly, nutrient deficiencies, low birth weight and maternal stress affect hypothalamic-pituitary-adrenal (HPA) axis development ${ }^{45}$ and this may be a key mechanism linking the early life environment with later disease risk. Exposure to an adverse in utero environment is associated with altered HPA axis activity in childhood and adulthood ${ }^{46} 47$ which may relate to the higher risk of neurodevelopmental problems, ${ }^{48}$ and changes in HPA axis activity are also a risk factor for CVD in later life. ${ }^{46}$ Finally, resetting of the HPA axis affects the development of key glucocorticoid responsive organs such as the kidneys, adipose tissue and pancreas, ${ }^{45}$ linking structural and hormonal changes in the programming of later life disease.

There has been much interest in recent years in the role of epigenetic modifications in early life programming. Epigenetic modifications lead to changes in gene expression that are not explained by changes in DNA sequence, and during normal development, key developmental stages are characterised by epigenetic modifications that have the potential to be altered/disrupted by environmental cues. Epigenetic modifications include DNA methylation, histone marks and small, non-coding RNAs.

DNA methylation is crucial for normal development and is involved in cell differentiation, genomic imprinting and $\mathrm{X}$ chromosome silencing. A growing number of studies have described alterations in DNA methylation and gene expression in association with early life exposures. Adults exposed in utero to severe calorie restriction during the Dutch Hunger Winter of $1944 / 1945$ have reduced methylation at regions controlling the expression of the insulin-like growth factor 2 (IGF2), a key hormone in growth and development ${ }^{49}$ and individuals exposed to an unbalanced diet in utero showed differential methylation at 11ß-hydroxysteroid dehydrogenase type 2 (important in the regulation of BP), the glucocorticoid receptor and IGF2, in association with a risk of obesity and hypertension. ${ }^{50}$ In rats, undernutrition and/or prenatal glucocorticoid overexposure influence DNA methylation of glucocorticoid receptor and IGF2 $2^{5152}$ suggesting a mechanism by which adverse early life environments may affect hormonal homoeostasis in offspring. Studies also suggest an association between maternal anxiety/depression and altered DNA methylation at genes important in HPA axis regulation and mood in the offspring. ${ }^{53}$ Such effects are also seen with postnatal exposures: experience of childhood abuse associates with altered HPA and autonomic responses to stress and with altered DNA methylation in peripheral blood and brain. ${ }^{54-56}$

DNA is organised around histones which can also be modified to control gene transcription. The development of glucose-insulin dyshomoeostasis in rats after IUGR is associated with alterations in histone modifications at the $P d x 1$ gene, a transcription factor regulating pancreatic development and $\beta$-cell differentiation, and additionally at the hepatic transcription factor $H n f 4 \alpha$, which associates with insulin resistance. ${ }^{57}$ Gene expression can also be modulated by non-coding RNAs which are posited to regulate gene expression by transcriptional and post-transcriptional gene silencing. Studies in adipose tissue of rats exposed to a low protein diet in utero and in humans born at low birth weight have demonstrated persistent changes in a specific micro-RNA which may influence adipocyte differentiation and maturation. ${ }^{58}$

Nevertheless, although studies have shown epigenetic changes in association with early life exposures, the degree to which such changes are adaptive within the life course, occur as a consequence of the induced disease state or represent a pathophysiological response to adverse exposures remains to be determined as the mechanism(s) of these changes are elucidated. Recent studies suggesting that a significant proportion of neonatal DNA methylation changes are determined by genotype rather than environment, ${ }^{59}$ highlight the difficulties in distinguishing genetic from epigenetic inheritance.

\section{INTERGENERATIONAL TRANSMISSION OF PROGRAMMED EFFECTS}

In addition to the effects of early life exposures on individual outcomes, there is increasing evidence that the effects of early life exposures may be transmitted non-genomically to subsequent generations. ${ }^{60}$ Three human cohort studies suggest possible instances of the transmission of programmed effects, two through the female line ${ }^{6162}$ and one patrilineally. ${ }^{63}$ In this latter study, Kaati et al used detailed historical information on cohorts from Sweden which showed that food availability during the grandparents' childhood influenced the risk of CVD and diabetes in their grandoffspring. Intergenerational effects of early life environmental interventions have also been shown in a number of animal models (reviewed in ref. 60). Potential explanations for the transmission of programming effects across generations include persisting adverse environmental conditions, adverse in utero experiences resulting in programming effects in a woman, which then influence her own pregnancy or effects that are transmissible through gametes, such as DNA methylation changes or non-coding RNAs ${ }^{60}$ (figure 2). Finally, the experience of maltreatment during childhood may result in subsequent harsh and/or neglectful parenting in adulthood and this could be perpetuated across a number of generations. ${ }^{64}$ These studies raise the possibility that antenatal, infant and childhood exposures may have consequences for multiple future generations. Indeed, intergenerational effects of the early life environment have been proposed as one mechanism to explain 
A

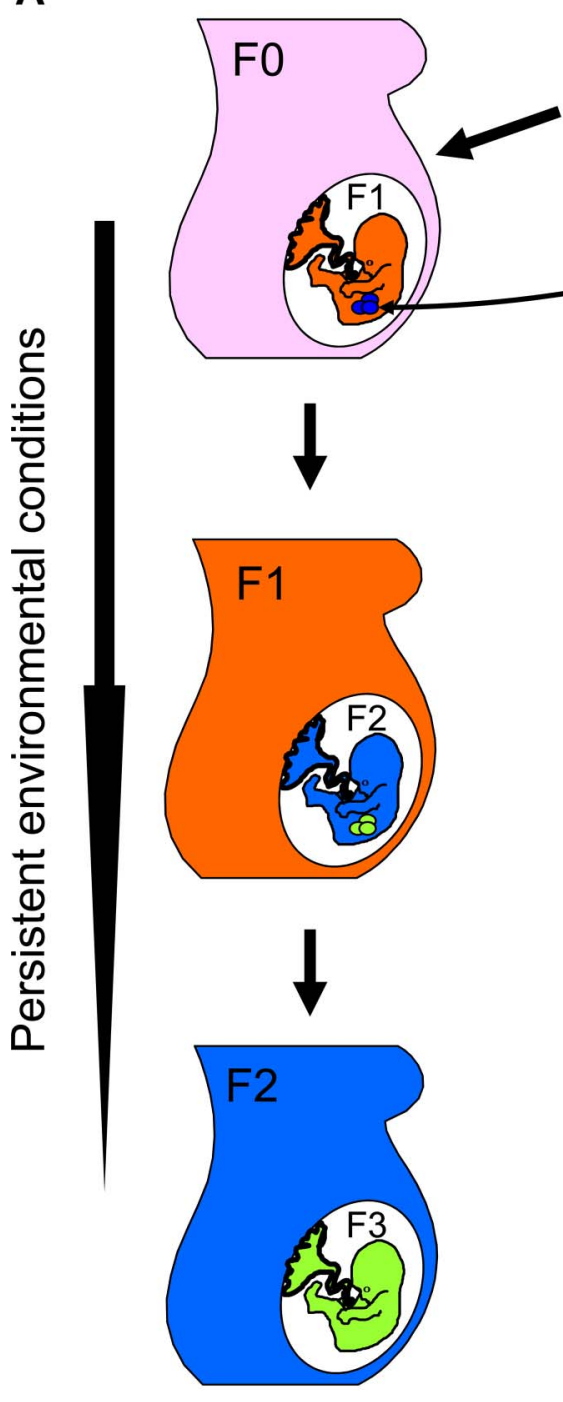

B

Initial insult to F0 mother and F1 fetus

Programming of F1 maternal physiology affects development of F2 offspring

\section{Programming of F2} maternal physiology affects development of F3 offspring
C

Insult also has direct effects on the germ cells which will form the F2 offspring

\section{Transgenerational transmission through the germline - induced effects persist in germ cells which will form F3 offspring}

Figure 2 Potential mechanisms accounting for the transgenerational transmission of disease risk. (A) Persistence of an adverse environment leads to the reinduction of programmed effects in each subsequent generation. (B) Maternal effects: the induction of programmed effects in the F1 offspring following in utero exposure lead to the induction of programmed effects on the developing F2 fetus and so on. (C) Exposure to an adverse environment affects the developing F1 fetus and has direct effects on the germ cells which will form the F2 generation and these changes are maintained in the germ cells for a number of subsequent generations.

persisting health disparities among disadvantaged populations, potentially through effects on the HPA axis. ${ }^{65} 66$

\section{SIGNIFICANCE FOR PAEDIATRICIANS}

An understanding of early life programming and its consequences is of clear importance for paediatricians who are ideally placed to identify those most at risk of later disease and to facilitate the development and implementation of interventions. Given that adverse early life environments may affect children's later life outcomes, and that of their own offspring, a paediatrician's role takes on important public health aspects.

First, we can influence care from the beginning of life by emphasising the importance of good maternal health and antenatal care in optimising child and adult health. Addressing modifiable risk factors, including maternal obesity, excess gestational weight gain, maternal smoking and vitamin $\mathrm{D}$ levels and breastfeeding duration ${ }^{10}$ could make a significant contribution to child health, and by implication, improve adult health. Indeed, paediatricians have been involved in the development of the National Institute for Health and Care Excellence evidencebased guidelines for the antenatal and postnatal care of women and babies (http://www.nice.org.uk) and these have been endorsed by the Royal College of Paediatrics and Child Health.

Since any effects of the in utero environment may be amplified as a consequence of early growth patterns, optimising early nutrition may be a key way in which paediatricians can influence later health. In preterm babies, studies are ongoing to develop nutritional strategies which optimise neurodevelopment and prevent extrauterine growth restriction without promoting the development of longer-term metabolic complications, ${ }^{67}$ however there is much less evidence for the optimal nutritional management of the SGA infant born at, or near term, ${ }^{68}$ or in the management of the offspring of obese women. Overweight and obese women are less likely than lean women to exclusively breastfeed at 2 months of age and are more likely to introduce early weaning foods. ${ }^{69}$ Breast feeding may be protective against childhood obesity as a consequence of reduced protein content compared with formula, the presence of active hormones such 
Figure 3 Intergenerational cycle of disease risk. Early life programming may result in effects which persist across generations. Paediatricians are well placed to identify those at risk and to develop and implement interventions at many points during the life-cycle. ADHD, attention deficit hyperactivity disorder; HPA axis, hypothalamic-pituitary-adrenal axis; NCD, non-communicable disease.

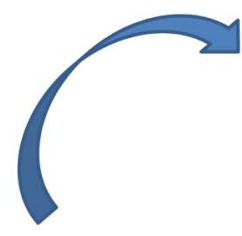

Neonate and infant Low birthweight

Shorter duration of breastfeeding Early weaning
Pregnancy

Poor pre-conceptual \& antenatal care

Poor diet

Obesity

Smoking

Hypertension

Activation HPA axis

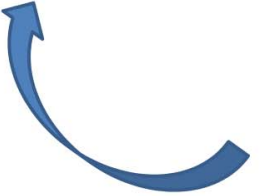

Adult

Poor diet

Obesity

Smoking

Low income

Activation HPA axis

Increased risk NCD
Childhood and adolescence Poor diet

Obesity

Increased risk ADHD \& behavioural disorders as leptin, ghrelin and adiponectin which may influence appetite control, and poorer regulation of satiety with bottle feeding. ${ }^{39}$ Thus, the provision of additional support for breast feeding and improving the food choices of these women has the potential to reduce childhood overweight and obesity, with obvious consequences for the next generation. ${ }^{69}$

There is ongoing research (at present mainly in animal models) investigating therapeutic options to reverse or prevent the effects of in utero programming. Studies are ongoing to evaluate strategies for the prevention of CVD in individuals born with IUGR. ${ }^{70}$ In animal studies, therapies which have been examined include micronutrient supplementation (eg, folate, glycine and choline) given during pregnancy to mitigate the effects of undernutrition, or statins for hypercholesterolaemia in pregnancy which may protect offspring against the conditioning effect of a high fat diet. ${ }^{4}$ Similarly, there may be a role for leptin and statin therapy in those born SGA to modify the long-term hormonal and cardiovascular effects of an adverse antenatal environment. ${ }^{4}$

Since programming effects may also occur as a consequence of experiences in infancy and childhood, targeted interventions during infancy and childhood may improve later health. For example a randomised controlled trial of the effects of additional support for single, poor, deprived mothers during pregnancy and first 2 years of life resulted in improved educational performance in childhood, less substance abuse at 12 years and less criminal behaviour at 19 years in their offspring. ${ }^{71}$ Importantly, evidence suggests that such interventions also have the potential to improve health outcomes across generations. ${ }^{65} 66$ Paediatricians could have a key role in identifying the factors which lead to the perpetuation of effects and in designing and implementing interventions to interrupt these intergenerational cycles $^{60}$ (figure 3).

In conclusion, paediatricians are ideally placed to undertake research leading to an increased understanding of the mechanisms underpinning early life programming, to develop strategies for the early identification of disease risk and finally, to design and implement therapeutic strategies, with consequences that may improve health for the children we care for, and for future generations.

Competing interests None declared.

Provenance and peer review Commissioned; externally peer reviewed.

\section{REFERENCES}

1 Kermack WO, McKendrick AG, McKinlay PL. Death rates in Great Britain and Sweden some general regularities and their significance. Lancet 1933;223:698-703.

2 Forsdahl A. Are poor living conditions in childhood and adolescence an important risk factor for arteriosclerotic heart disease? Br J Prev Soc Med 1977;31:91-5.

3 Barker DJ, Osmond C. Infant mortality, childhood nutrition, and ischaemic heart disease in England and Wales. Lancet 1986;1:1077-81.

4 Hanson MA, Gluckman PD. Early developmental conditioning of later health and disease: physiology or pathophysiology? Physiol Rev 2014;94:1027-76.

5 Martin-Gronert M, Ozanne S. Mechanisms underlying the developmental origins of disease. Rev Endocr Metab Disord 2012;13:85-92.

6 Moore SE, Collinson AC, Tamba N, et al. Early immunological development and mortality from infectious disease in later life. Proc Nutr Soc 2006;65:311-18.

7 Steffensen FH, Sørensen HT, Gillman MW, et al. Low birth weight and preterm delivery as risk factors for asthma and atopic dermatitis in young adult males. Epidemiology 2000;11:185-8.

8 Linnet KM, Wisborg K, Agerbo E, et al. Gestational age, birth weight, and the risk of hyperkinetic disorder. Arch Dis Child 2006;91:655-60.

9 Nilsson E, Stalberg G, Lichtenstein $P$, et al. Fetal growth restriction and schizophrenia: a Swedish twin study. Twin Res Hum Genet 2005;8:402-8.

10 Robinson SM, Crozier SR, Harvey NC, et al. Modifiable early-life risk factors for childhood adiposity and overweight: an analysis of their combined impact and potential for prevention. Am J Clin Nutr 2015;101:368-75.

11 Lazdam M, de la Horra A, Pitcher A, et al. Elevated blood pressure in offspring born premature to hypertensive pregnancy: is endothelial dysfunction the underlying vascular mechanism? Hypertension 2010;56:159-65.

12 Mamun AA, O'Callaghan MJ, Williams GM, et al. Maternal smoking during pregnancy predicts adult offspring cardiovascular risk factors - evidence from a community-based large birth cohort study. PLOS ONE 2012;7:e41106.

13 Parkinson JRC, Hyde MJ, Gale C, et al. Preterm birth and the metabolic syndrome in adult life: a systematic review and meta-analysis. Pediatrics 2013;131: e1240-e63.

14 Bayman E, Drake AJ, Piyasena C. Prematurity and programming of cardiovascular disease risk: a future challenge for public health? Arch Dis Child Fetal Neonatal Ed 2014;99:F510-14

15 Drake AJ, Reynolds RM. Impact of maternal obesity on offspring obesity and cardiometabolic disease risk. Reproduction 2010;140:387-98.

16 Rodriguez A. Maternal pre-pregnancy obesity and risk for inattention and negative emotionality in children. J Child Psychol Psychiatry 2010;51:134-43.

17 Reynolds RM, Allan KM, Raja EA, et al. Maternal obesity during pregnancy and premature mortality from cardiovascular event in adult offspring: follow-up of 1323 275 person years. BMJ 2013;347:f4539.

18 Harville EW, Xiong X, Buekens P. Disasters and perinatal health: a systematic review. Obstet Gynecol Surv 2010;65:713-28.

19 Laplante DP, Brunet A, Schmitz N, et al. Project Ice Storm: prenatal maternal stress affects cognitive and linguistic functioning in 5 1/2-year-old children. J Am Acad Child Adolesc Psychiatry 2008;47:1063-72.

20 Rieger M, Pirke K-M, Buske-Kirschbaum A, et al. Influence of stress during pregnancy on HPA activity and neonatal behavior. Ann N Y Acad Sci 2004;1032:228-30. 
21 O'Connor TG, Heron J, Golding J, et al. Maternal antenatal anxiety and children's behavioural/emotional problems at 4 years: report from the Avon Longitudinal Study of Parents and Children. Br J Psychiatry 2002;180:502-8.

22 Buss C, Davis EP, Muftuler LT, et al. High pregnancy anxiety during mid-gestation is associated with decreased gray matter density in 6-9-year-old children. Psychoneuroendocrinology 2010;35:141-53.

23 Hirvikoski T, Nordenstrom A, Lindholm T, et al. Cognitive functions in children at risk for congenital adrenal hyperplasia treated prenatally with dexamethasone. J Clin Endocrinol Metab 2007;92:542-8.

24 Khulan B, Drake AJ. Glucocorticoids as mediators of developmental programming effects. Best Pract Res Clin Endocrinol Metab 2012;26:689-700.

25 Lo C-L, Zhou FC. Environmental alterations of epigenetics prior to the birth. In: Subhash CP. ed. International review of neurobiology. Academic Press, 2014:1-49.

26 Singhal A, Cole TJ, Fewtrell $M$, et al. Promotion of faster weight gain in infants born small for gestational age: Is there an adverse effect on later blood pressure? Circulation 2007;115:213-20.

27 Nowson CA, Crozier SR, Robinson SM, et al. Association of early childhood abdominal circumference and weight gain with blood pressure at 36 months of age: secondary analysis of data from a prospective cohort study. BMJ Open 2014;4 e005412.

28 Jain V, Singhal $A$. Catch up growth in low birth weight infants: striking a healthy balance. Rev Endocr Metab Disord 2012;13:141-7.

29 Barker DJP, Kajantie E, Osmond C, et al. How boys grow determines how long they live. Am J Hum Biol 2011;23:412-6.

30 Eriksson JG. Early growth and coronary heart disease and type 2 diabetes: findings from the Helsinki Birth Cohort Study (HBCS). Am J Clin Nutr 2011;94:1799S-802S

31 Ozanne SE, Hales CN. Catch-up growth and obesity in male mice. Nature 2004:427:411-2

32 Hofman $\mathrm{PL}$, Regan F, Jackson WE, et al. Premature birth and later insulin resistance. N Engl J Med 2004;351:2179-86.

33 Mathai S, Cutfield WS, Derraik JGB, et al. Insulin sensitivity and $\beta$-cell function in adults born preterm and their children. Diabetes 2012:61:2479-83.

34 Rowe DL, Derraik JGB, Robinson E, et al. Preterm birth and the endocrine regulation of growth in childhood and adolescence. Clin Endocrinol 2011;75:661-5.

35 Mathai S, Derraik JGB, Cutfield WS, et al. Increased adiposity in adults born preterm and their children. PLOS ONE 2013;8:e81840.

36 Singhal A, Fewtrell M, Cole TJ, et al. Low nutrient intake and early growth for later insulin resistance in adolescents born preterm. Lancet 2003;361:1089-97.

37 Bazaes RA, Alegría A, Pittaluga $E$, et al. Determinants of insulin sensitivity and secretion in very-low-birth-weight children. J Clin Endocrinol Metab 2004;89:1267-72.

38 Rotteveel J, van Weissenbruch MM, Twisk JWR, et al. Infant and childhood growth patterns, insulin sensitivity, and blood pressure in prematurely born young adults. Pediatrics 2008;122:313-21.

39 Katzmarzyk PT, Barlow S, Bouchard C, et al. An evolving scientific basis for the prevention and treatment of pediatric obesity. Int J Obes 2014;38:887-905.

40 Drake AJ, Raubenheimer PJ, Kerrigan D, et al. Prenatal dexamethasone programs expression of genes in liver and adipose tissue and increased hepatic lipid accumulation but not obesity on a high-fat diet. Endocrinology 2010;151:1581-7.

41 Eriksson M, Räikkönen K, Eriksson JG. Early life stress and later health outcomesfindings from the Helsinki Birth Cohort Study. Am J Hum Biol 2014;26:111-16.

42 Manalich $R$, Reyes L, Herrera $M$, et al. Relationship between weight at birth and the number and size of renal glomeruli in humans: a histomorphometric study. Kidney Int 2000;58:770-3.

43 Lewandowski AJ, Davis EF, Yu G, et al. Elevated blood pressure in preterm-born offspring associates with a distinct antiangiogenic state and microvascular abnormalities in adult life. Hypertension 2015;65:607-14.

44 Blondeau B, Lesage J, Czernichow $\mathrm{P}$, et al. Glucocorticoids impair fetal beta-cell development in rats. Am J Physiol Endocrinol Metab 2001;281:E592-9.

45 Xiong F, Zhang L. Role of the hypothalamic-pituitary-adrenal axis in developmental programming of health and disease. Front Neuroendocrinol 2013;34:27-46.

46 Reynolds RM, Walker BR, Syddall HE, et al. Altered control of cortisol secretion in adult men with low birth weight and cardiovascular risk factors. J Clin Endocrinol Metab 2001;86:245-50.

47 Jones $A$, Godfrey KM, Wood $P$, et al. Fetal growth and the adrenocortical response to psychological stress. J Clin Endocrinol Metab 2006;91:1868-71.
48 Mina TH, Reynolds RM. Mechanisms linking in utero stress to altered offspring behaviour. Curr Top Behav Neurosci 2014:18:93-122.

49 Heijmans BT, Tobi EW, Stein AD, et al. Persistent epigenetic differences associated with prenatal exposure to famine in humans. PNAS 2008;105:17046-9.

50 Drake AJ, McPherson RC, Godfrey KM, et al. An unbalanced maternal diet in pregnancy associates with offspring epigenetic changes in genes controlling glucocorticoid action and foetal growth. Clin Endocrinol 2012;77:808-15.

51 Drake AJ, Liu L, Kerrigan D, et al. Multigenerational programming in the glucocorticoid programmed rat is associated with generation-specific and parent of origin effects. Epigenetics 2011;6:1334-43.

52 Burdge GC, Slater-Jefferies JL, Torrens $C$, et al. Dietary protein restriction of pregnant rats in the $\mathrm{FO}$ generation induces altered methylation of hepatic gene promoters in the adult male offspring in the F1 and F2 generations. Br J Nutr 2007:97:435-9

53 Devlin AM, Brain U, Austin J, et al. Prenatal exposure to maternal depressed mood and the MTHFR C677T variant affect SLC6A4 methylation in infants at birth. PLOS ONE 2010:5:e12201.

54 Suderman M, Borghol N, Pappas J, et al. Childhood abuse is associated with methylation of multiple loci in adult DNA. BMC Medical Genomics 2014;7:13.

55 McGowan PO, Sasaki A, D'Alessio AC, et al. Epigenetic regulation of the glucocorticoid receptor in human brain associates with childhood abuse. Nat Neurosci 2009;12:342-8.

56 Heim C, Newport D, Heit S, et al. Pltuitary-adrenal and autonomic responses to stress in women after sexual and physical abuse in childhood. JAMA 2000;284:592-7.

57 Park JH. Development of type 2 diabetes following intrauterine growth retardation in rats is associated with progressive epigenetic silencing of Pdx1. J Clin Invest 2008:118:2316-24.

58 Ferland-McCollough D, Fernandez-Twinn DS, Cannell IG, et al. Programming of adipose tissue miR-483-3p and GDF-3 expression by maternal diet in type 2 diabetes. Cell Death Differ 2012;19:1003-12.

59 Teh $A \mathrm{~L}$, Pan $\mathrm{H}$, Chen $\mathrm{L}$, et al. The effect of genotype and in utero environment on interindividual variation in neonate DNA methylomes. Genome Res 2014;24:1064-74.

60 Drake AJ, Liu L. Intergenerational transmission of programmed effects: public health consequences. Trends Endocrinol Metab 2010;21:206-13.

61 Baird D. Changing problems and priorities in obstetrics. Br J Obstet Gynaecol 1985;92:115-21.

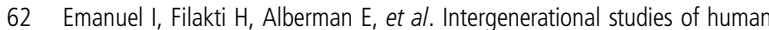
birthweight from the 1958 birth cohort. 1. Evidence for a multigenerational effect. Br J Obstet Gynaecol 1992:99:67-74

63 Kaati G, Bygren LO, Edvinson S. Cardiovascular and diabetes mortality determined by nutrition during parents' and grandparents' slow growth period. Eur J Hum Genet 2002;10:682-8.

64 Merrick MT, Leeb RT, Lee RD. Examining the role of safe, stable, and nurturing relationships in the intergenerational continuity of child maltreatment-introduction to the special issue. J Adoles Health 2013;53:S1-3.

65 Kuzawa CW, Sweet E. Epigenetics and the embodiment of race: developmental origins of US racial disparities in cardiovascular health. Am J Hum Biol 2009:21:2-15.

66 Thayer ZM, Kuzawa CW. Biological memories of past environments. Epigenetic pathways to health disparities. Epigenetics 2011;6:1-6.

67 Lafeber HN, van de Lagemaat M, Rotteveel J, et al. Timing of nutritional interventions in very-low-birth-weight infants: optimal neurodevelopment compared with the onset of the metabolic syndrome. Am J Clin Nutr 2013;98:556S-60S.

68 Tudehope $D$, Vento $M$, Bhutta $Z$, et al. Nutritional requirements and feeding recommendations for small for gestational age infants. J Pediatr 2013;162:S81-9.

69 Thompson AL. Intergenerational impact of maternal obesity and postnatal feeding practices on pediatric obesity. Nutr Rev 2013;71:S55-61.

70 Skilton MR, Ayer JG, Harmer JA, et al. Impaired fetal growth and arterial wall thickening: a randomized trial of omega-3 supplementation. Pediatrics 2012;129: e698-703.

71 Eckenrode J, Campa M, Luckey DW, et al. Long-term effects of prenatal and infancy nurse home visitation on the life course of youths: 19-year follow-up of a randomized trial. Arch Pediatr Adolesc Med 2010;164:9-15. 